\title{
Thermal and Electrical Properties of Carbon Nanotube Based Materials
}

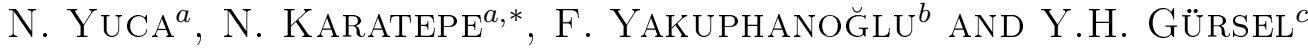 \\ ${ }^{a}$ Energy Institute, Istanbul Technical University, Istanbul 34469, Turkey \\ ${ }^{b}$ Physics Department, Firat University, Elazig 23169, Turkey \\ ${ }^{c}$ Chemical Department, Istanbul Technical University, Istanbul 34469, Turkey
}

\begin{abstract}
In this study, carbon nanotubes were synthesized at temperatures of $500{ }^{\circ} \mathrm{C}$ and $800{ }^{\circ} \mathrm{C}$ by the fluidized-bed chemical vapor deposition method. The synthesized material was purified by using $3 \mathrm{M} \mathrm{HCl}$ at $75^{\circ} \mathrm{C}$, $15 \mathrm{~h}$. After synthesis and purification, the polyaniline-doped $\mathrm{H}_{3} \mathrm{BO}_{3}$ and $\mathrm{BF}_{3}$ and composites were prepared by coagulation method. Transmission electron microscope and Fourier transform infrared spectroscopy were used to characterize the carbon nanotubes and their composites. Thermal stabilities were measured by thermogravimetry and differential scanning calorimetry instruments. The thermogravimetry and derivative thermogravimetry curves indicated that the thermal stability of polyaniline-doped $\mathrm{H}_{3} \mathrm{BO}_{3}$ and $\mathrm{BF}_{3}$ increased with carbon nanotube doping. The electrical properties of carbon nanotubes and their composites were also determined. The obtained electrical conductivity values of the nanocomposites including the polyaniline-doped $\mathrm{H}_{3} \mathrm{BO}_{3}$ and $\mathrm{BF}_{3}$ were typical for organic semiconductor materials. It can be evaluated that the electrical properties of the polyaniline based polymers can be controlled by carbon nanotube doping.
\end{abstract}

DOI: 10.12693/APhysPolA.123.352

PACS: 81.05.U-

\section{Introduction}

Carbon nanotubes (CNTs), discovered by Iijima et al. [1], have remarkable properties, such as mechanical strength, flexibility, chemical stability, electrical and thermal conductivity. These behaviors have made them very promising nanomaterials for new applications in chemistry and physics, particularly for the development of new nanotechnologies and devices [2]. For instance, experimentally doping CNTs into a polymer matrix improves the electrical conductivity, mechanical and thermal properties of the original polymer matrix and this is substantial for polymer-based devices [3-6]. Recent measurements showed that the presence of CNTs increases the thermal stability of polymer matrix. Ge et al. [7] found that the thermal stability $\left(T_{i}\right)$ of polyacrylonitrile (PAN) increased from $268^{\circ} \mathrm{C}$ to $292^{\circ} \mathrm{C}$ after $5 \mathrm{wt} \%$ multiwall carbon nanotubes (MWCNTs) addition that was sythesized by chemical vapor deposition (CVD) method by using Fe catalyst. McNally et al. [8] also synthesized MWCNTs by using CVD method and showed that $10 \mathrm{wt} \%$ MWCNTs increased the thermal stability $\left(T_{p}\right)$ of polyethylene (PE) from $400^{\circ} \mathrm{C}$ to $420^{\circ} \mathrm{C}$. The electrical conductivities of the polyaniline (PANI) containing boron/double wall carbon nanotubes composites prepared with $1 \%, 5 \%$, and $8 \%$ CNT concentrations at $27^{\circ} \mathrm{C}$ were found to be $5.31 \times 10^{-6}, 2.72 \times 10^{-4}$, and $1.12 \times 10^{-3}(\mathrm{~S} / \mathrm{cm})$, respectively by Yakuphanoğlu et al. [9]. Deng et al. [10] proposed that even $0.2 \%$ of CNTs can improve the conductivity of the CNT/PANI composite more than three times than that of PANI.

* corresponding author

\section{Experimental studies}

\subsection{Synthesis and characterization of materials}

Carbon nanotubes were synthesized by the fluidized-bed CVD of acetylene $\left(\mathrm{C}_{2} \mathrm{H}_{2}\right)$ on a magnesium oxide $(\mathrm{MgO})$ powder impregnated with an iron nitrate $\left(\mathrm{Fe}\left(\mathrm{NO}_{3}\right)_{3} \cdot 9 \mathrm{H}_{2} \mathrm{O}\right)$ solution. The synthesis parameters were selected as: the synthesis temperatures of 500 and $800{ }^{\circ} \mathrm{C}$, the iron content in the precursor of $5 \%$ and the synthesis time of $30 \mathrm{~min}$. The synthesized material was purified by using $\mathrm{HCl}$ at $75^{\circ} \mathrm{C}, 15 \mathrm{~h}$. After synthesis of CNTs, the polyaniline-doped $\mathrm{H}_{3} \mathrm{BO}_{3}$ and $\mathrm{BF}_{3}$ and composites were prepared by coagulation method and the weight percentage of CNTs was selected as $10 \%$. In the coagulation method, dimethyl formamide (DMF) was chosen to dissolve the PANI-B and PANI-BF ${ }_{3}$ polymer and to permit the dispersion of the CNTs by bath sonication for $10 \mathrm{~h}$. The composites were obtained by evaporating DMF from the solutions. The synthesized CNTs and composites were characterized by TEM-FEI Tecnai-G2 F-20 instrument, FT-IR spectroscopy-Perkin Elmer spectrum one and TGA-TA-Q600 SDT instrument.

\subsection{Thermal stability and electrical conductivity measurement}

The thermogravimetry (TG) and derivative thermogravimetry (DTG) analyses (TA-Q600 SDT instrument) were conducted to identify the thermal stability of CNTs. TG curves were obtained under air atmosphere at a heating rate of $5^{\circ} \mathrm{C} / \mathrm{min}$ from room temperature to $800^{\circ} \mathrm{C}$. The electrical conductivity measurement of prepared samples was performed by electrometer of Keithley $6517 \mathrm{~A}$. The measurement was achieved at $20^{\circ} \mathrm{C}$ temperature under $1 \mathrm{~V}$ electrical current. Thickness of the samples was measured by digital micrometer. 


\section{Results and discussion}

By varying the synthesis temperature from 500 to $80{ }^{\circ} \mathrm{C}$ at a fixed iron content of $5 \%$, a synthesis time of 30 min and acetylene as carbon source the yield were obtained in different nanotube type. TEM images of these yields are given in Fig. 1. It is seen from Fig. 1a and b that the structures which were synthesized by chemical vapor deposition method are CNTs. In Fig. 1a, the diameter of the CNTs is $10 \mathrm{~nm}$ and their appearance is darker in the picture. The CNTs in Fig. 1b have diameters nearly between $1.5-5 \mathrm{~nm}$ and also are so transparent. One possible explanation for the dark parts in both two figures is a result of the impurities within the structures. These observations lead to a conclusion: in the temperature of $500{ }^{\circ} \mathrm{C}$ MWCNTs were grown and at the temperature of $800^{\circ} \mathrm{C}$ singlewall carbon nanotubes (SWCNTs) were synthesized. TEM images of the composite materials which were prepared by using polyaniline-doped $\mathrm{H}_{3} \mathrm{BO}_{3}$ and $\mathrm{BF}_{3}$ are also given in Fig. $1 \mathrm{c}$ and d. These results indicate that CNTs were well dispersed in the polymer matrix with no apparent damage.

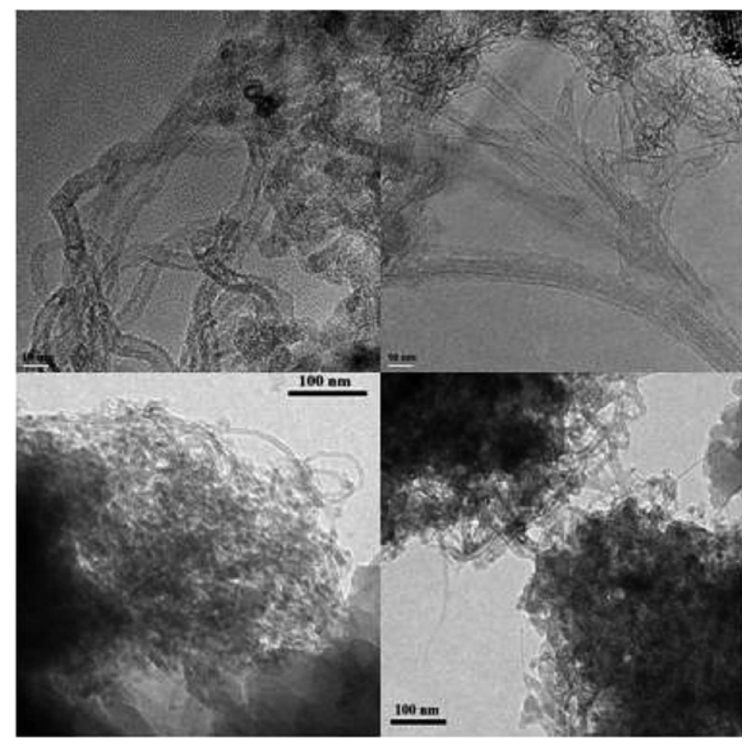

Fig. 1. TEM images of CNTs and composites (a) MWCNT, (b) SWCNT, (c) CNT/PANI-BF 3 , (d) CNT/ PANI-B.

Figure 2 exhibits the FTIR spectra of MWCNTs, SWCNTs, PANI-B/CNTs and PANI-BF $3 / \mathrm{CNTs}_{3}$ (10 wt\%) composites. It can be obviously seen that the peaks of pure PANI-B and PANI-BF ${ }_{3}$ were in good agreement with those reported in the literature [11]. The main characteristic bands of doped polyaniline and CNTs (MWCNT and SWCNT) appear in the FTIR spectra of the composites (10 wt\%) prepared. The band at about $1141 \mathrm{~cm}^{-1}$ is assigned to a plane bending vibration of $\mathrm{C}-\mathrm{H}$ (mode of $\mathrm{N}=\mathrm{Q}=\mathrm{N}, \mathrm{Q}=\mathrm{N}^{+} \mathrm{H}-\mathrm{B}$ and $\mathrm{B}-\mathrm{N}{ }^{+} \mathrm{H}-\mathrm{B}$ ), which is formed during protonation. The bands at $1568 \mathrm{~cm}^{-1}$ and $1287 \mathrm{~cm}^{-1}$, corresponding to the stretch- ing mode of $\mathrm{C}=\mathrm{N}$ and $\mathrm{C}-\mathrm{N}$, shift to lower wave numbers. This phenomenon is similar to Ref. [12] because of the interaction between CNTs sidewalls and PANI chains.

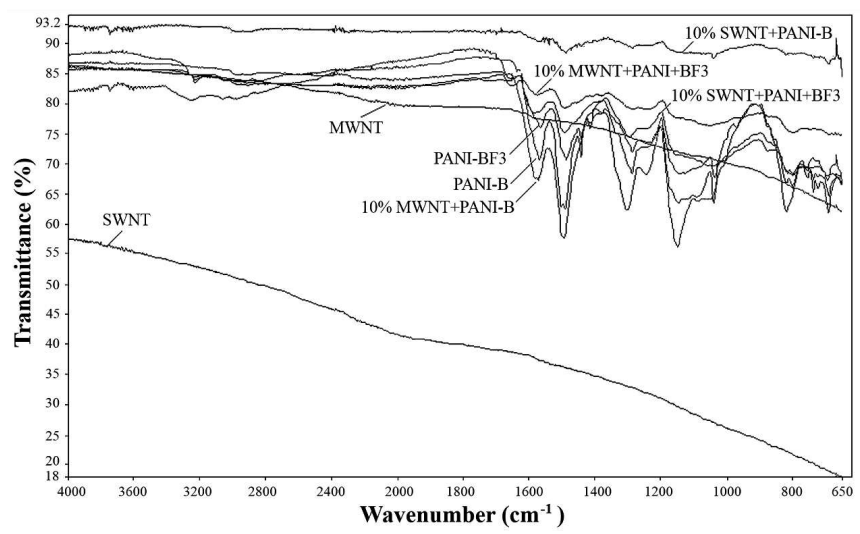

Fig. 2. FTIR spectra of CNTs and composites.

TG analysis was used to characterize the total carbon loading and determine the residual metallic catalyst. As shown in Fig. 3, there have been observed very low metallic catalyst amount of CNTs and a marked difference between combustion rates of MWCNTs and SWCNTs, where MWCNTs have two peaks whereas SWCNTs have one peak. The reason for the extra peak in MWCNTs is the existence of amorphous carbon and oxidation at low temperatures due to the low thermal stability.

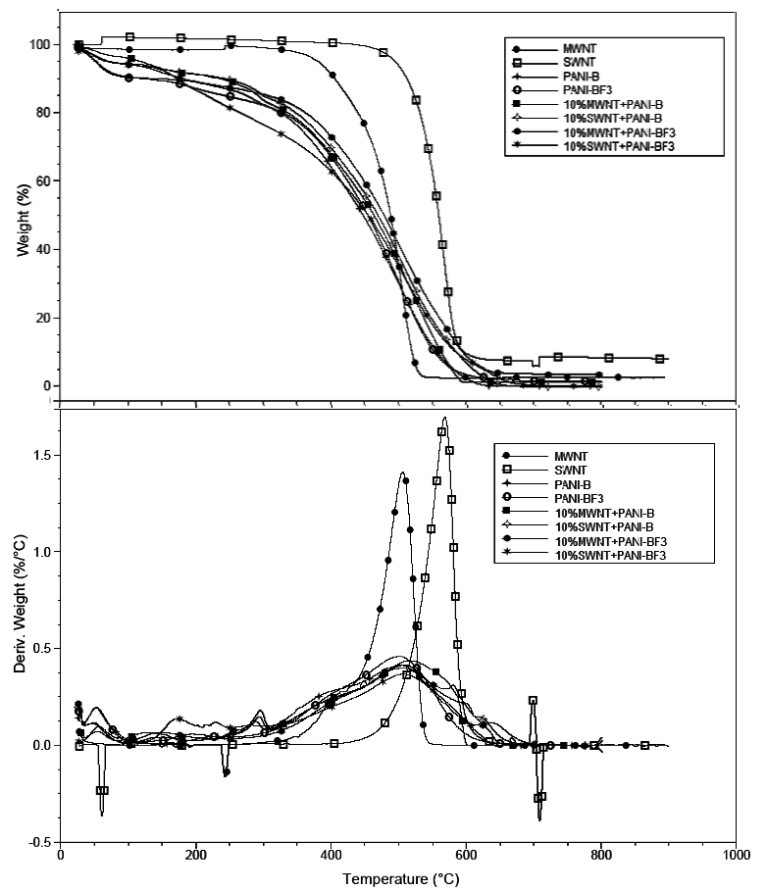

Fig. 3. TG and DTG curves of CNTs and composites.

Figure 3 also presents the TG and DTG curves of PANI-B/CNTs $(10 \mathrm{wt} \%)$ and PANI-BF $3 / \mathrm{CNTs}_{3}(10 \mathrm{wt} \%)$ 
composites. According to the DTG curves, $T_{i}$ (the initial degradation temperature) and $T_{p}$ (peak temperature which corresponds to the maximum weight loss of the sample) values of composites are given in Table. It can be seen that $T_{i}$ and $T_{p}$ values of the PANI-B and PANI$-\mathrm{BF}_{3}$ are lower than composites. It is determined that the thermal stability of the PANI-B and PANI-BF ${ }_{3}$ increase depending on the CNT addition. The increase in $T_{p}$ was due to the interaction between polymer (PANI-B and PANI-BF 3 ) chains and CNTs which inhibited the degradation speed of polymers.

TABLE

Thermal properties and electrical conductivity of samples.

\begin{tabular}{|c|c|c|c|c|}
\hline Sample & $T_{i}\left[{ }^{\circ} \mathrm{C}\right]$ & $T_{p}\left[{ }^{\circ} \mathrm{C}\right]$ & $T_{g}\left[{ }^{\circ} \mathrm{C}\right]$ & {$[\mathrm{S} / \mathrm{cm}]$} \\
\hline MWCNT & 419 & 511 & - & 4.99 \\
\hline SWCNT & 476 & 590 & - & 2.224 \\
\hline PANI-B & 302 & 503 & 151 & $3.42 \times 10^{-5}$ \\
\hline PANI-BF 3 & 286 & 500 & 155 & $6.12 \times 10^{-5}$ \\
\hline PANI-B+MWCNT $10 \%$ & 313 & 518 & 170 & $1.54 \times 10^{-4}$ \\
\hline PANI-BF ${ }_{3}+\mathrm{MWCNT} 10 \%$ & 303 & 510 & 159 & $8.26 \times 10^{-4}$ \\
\hline PANI-B+SWCNT10\% & 312 & 512 & 171 & $4.20 \times 10^{-5}$ \\
\hline 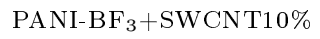 & 306 & 508 & 158 & $1.17 \times 10^{-4}$ \\
\hline
\end{tabular}

Glass transition behavior of composites were also studied by DSC and the results are given in Table. It can be seen from the results that $T_{g}$ values of polymers increased with CNT addition. It may be because that with CNT addition of $10 \mathrm{wt} \%$, the quantity of polymer chains, which grew along the sidewalls of CNTs, increases.

The electrical conductivities of the CNTs and composites were measured and the results are given in Table. It is seen from the results that CNTs addition increases the electrical conductivity values of polymers. The reason of this increment that with CNT addition of $10 \mathrm{wt} \%$, the quantity of polymer chains increased.

This observation lead to a conclusion: the electrical conductivity values for the CNT composite were typical for organic semiconductor materials.

\section{Conclusion}

This study indicates that the thermal stability and electrical conductivity of CNT composites which were synthesized by coagulation method varied depending on the addition of CNTs. It was determined that the thermal stability of PANI-B and PANI-BF ${ }_{3}$ increased when the CNTs were added. Furthermore, the electrical conductivity values of the CNT composites which were found within the range of $3.42 \times 10^{-5}$ and $8.26 \times 10^{-4} \mathrm{~S} / \mathrm{cm}$ increased with addition of CNTs.

\section{References}

[1] S. Iijima, T. Ichihashi, Nature 363, 603 (1993).

[2] J.N.R. Rao, A.K. Cheetham, J. Mater. Chem. 11, 2887 (2001)

[3] H.S. Woo, R. Czerw, S. Webster, D.L. Carroll, Synth. Met. 116, 369 (2001)

[4] E. Kymakis, G.A. Amaratunga, J. Appl. Phys. Lett. 80, 112 (2002).

[5] H. Ago, K. Petritsch, M.S.P. Shaffer, A.H. Windle, R.H. Friend, Adv. Mater. 11, 1281 (1999)

[6] S.A. Curran, P.M. Ajayan, W.J. Blau, D.L. Carroll, Adv. Mater. 10, 1091 (1998).

[7] J.J. Ge, H. Hou, Q. Li, M.J. Graham, A. Greiner, D.H. Reneker, J. Am. Chem. Soc. 126, 15754 (2004)

[8] T. McNally, P. Pötschke, P. Halley, M. Murphy, D. Martin, S.E.J. Bell, Polymer 46, 8222 (2005)

[9] Y. Yakuphanoğlu, F. Şenkal, Polym. Adv. Technol. 19, 905 (2008).

[10] J. Deng, X. Ding, W. Zhang, Y. Peng, J. Wang, X. Long, P. Li, A.S.C. Chan, Eur. Polym. J. 38, 2497 (2002)

[11] H. Zhang, H.X. Li, H.M. Cheng, J. Phys. Chem B 110, 9095 (2006)

[12] Y. Yu, B. Che, Z. Si, L. Li, W. Chen, G. Xue, Synth. Met. 150, 271 (2005) 